This manuscript has been submitted for peer reviewing in Earth and Planetary Sciences Letters on November 15, 2018. If published, the final manuscript might have slightly different content and will be available via his peer-reviewed publication DOI. 


\section{Ridge Subduction and Afterslip Control Aftershock Distribution of the 2016 Mw 7.8 Ecuador Earthquake}

H. Agurto-Detzel, Y. Font, P. Charvis, M. Régnier, A. Rietbrock, D. Ambrois, M. Paulatto, A. Alvarado, S. Beck, M.J. Hernandez, S. Hernandez, M. Hoskins, S. León-Ríos, C. Lynner, A. Meltzer, D. Mercerat, F. Michaud, J.M. Nocquet, F. Rolandone, M. Ruiz, L. Soto-Cordero Corresponding author:HAD agurto@geoazur.unice.fr h.agurto.detzel@gmail.com

\section{Abstract}

We characterise the aftershock sequence following the $2016 \mathrm{Mw}=7.8$ Pedernales earthquake. More than 10,000 events were detected and located, with magnitudes up to 6.9. Most of the aftershock seismicity results from interplate thrust faulting, but we also observe a few normal and strike-slip mechanisms. Seismicity extends for more than $300 \mathrm{~km}$ along strike, and is constrained between the trench and the maximum depth of the coseismic rupture. The most striking feature is the presence of three seismicity bands, perpendicular to the trench, which are also observed during the interseismic period. Additionally, we observe a linear dependency between the temporal evolution of afterslip and aftershocks. We also find a temporal semi-logarithmic expansion of aftershock seismicity along strike and dip directions, further indicating that their occurrence is modulated by afterslip. Lastly, we observe that the spatial distribution of seismic and aseismic slip processes is correlated to the distribution of bathymetric anomalies associated with the northern flank of the Carnegie Ridge, suggesting that slip in the area could be influenced by the relief of the subducting seafloor. To explain our observations, we propose a conceptual model in which the Ecuadorian margin is subject to a bimodal slip mode, with distributed seismic and aseismic slip mechanically controlled by the subduction of a rough oceanic relief. Our study sheds new light on the mechanics of subduction, relevant for convergent margins with a complex and heterogeneous structure such as the Ecuadorian margin.

Keywords: Aftershock; Subduction; Afterslip; Ecuador; Carnegie Ridge; Seafloor Relief; 


\section{Introduction}

32 The largest earthquakes on Earth occur in subduction zones, which also host a diversity of 33 processes including seismic and aseismic slip along the subduction interface (e.g. Bilek and 34 Lay, 2018, and references therein). What controls the occurrence and distribution of these phenomena remains an outstanding problem in Earth sciences. One way to gain a better insight into the nature of the subduction mechanism and the physical medium that host them, is by studying the aftershocks sequence that follows a large megathrust earthquake. Moreover, the high rate of seismicity during aftershock sequences, combined with recent technological and logistical improvements in seismological network deployments and data processing (e.g. Beck et al., 2014), allows us to collect and analyse vast amounts of data with increased spatio-temporal resolution.

Aftershocks occur either because of the release of residual stresses on the mainshock fault and surrounding medium, or as a result of static or dynamic stress perturbations due to the coseismic rupture and subsequent aftershocks (e.g. Das and Henry, 2003; Freed, 2005).

Consequently, aftershocks can provide an independent constraint in the shape and extension of the rupture area and interface heterogeneities, as well as help us identify areas of partially released and/or accumulated stress over the megathrust interface following the mainshock, thus delineating potential source areas for future earthquakes.

50 The often intricate distribution of aftershocks accounts for a complex distribution of 51 remaining stresses and interface heterogeneities following the mainshock. For instance, after the $2005 \mathrm{Mw}=8.7$ Nias-Simeulue earthquake in Sumatra, Hsu et al. (2006) found that aftershocks clustered in the boundary area between the coseismic rupture and the afterslip

54 area, with afterslip concentrated mostly up-dip of the coseismic rupture. Furthermore, it is often observed that regions of large co-seismic slip tend to have little seismicity after the 
mainshock rupture, whilst the largest aftershocks concentrate around the patches of large coseismic slip (e.g. Das and Henry, 2003; Rietbrock et al., 2012; Agurto et al., 2012; Wetzler et al., 2018). On the other hand, aftershock activity is not only limited to the megathrust interface, but also to the surrounding seismogenic volume, often showing a diversity of focal mechanisms and complex interactions between activity in the slab and in the overriding plate (e.g. Asano et al., 2011). Lastly, for some subduction earthquakes, such as the 2011 Tohoku, Japan earthquake, the reduction of shear stresses after the mainshock is such that it produces a rotation of the deviatoric stress field, potentially causing extensional earthquakes in a previously compressional setting (e.g. Ryder et al., 2012; Hardebeck, 2012).

Moreover, the physics behind aftershock generation is still not fully understood. Aftershocks were first described and used as a proxy for the mainshock rupture extension, and subsequently explained as ruptures on surrounding faults due to the re-distribution of strain energy following the mainshock. Consequently, aftershocks triggering mechanism would be related to dynamic and/or static stress transfers, following the mainshock and subsequent aftershocks (Stein, 1999). More recently, observational and theoretical studies have proposed that afterslip plays an important role in the occurrence and distribution of aftershocks (e.g. Henry and Das, 2001; Perfettini et al., 2018). For example, following the $2005 \mathrm{Mw}=8.7 \mathrm{Nias}-$ Simeulue earthquake in Sumatra, Hsu et al. (2006) found that the cumulative number of aftershocks increased linearly with the postseismic displacement, suggesting that the temporal evolution of aftershocks is governed by afterslip.

On the 16 of April 2016, a Mw=7.8 earthquake struck the coast of northern Ecuador rupturing a $\sim 100 \mathrm{~km}$-long asperity of the interface between the Nazca plate and South America (Nocquet et al., 2017). Shortly after the mainshock, we deployed an amphibious 
81 temporary network of seismic stations to monitor the evolution of the seismic activity. In this paper, we benefit from the continuous seismic waveform dataset acquired during one year of the aftershock deployment to explore the distribution of hypocentral locations and magnitudes for the Pedernales sequence. We also use full waveform inversions to compute moment tensors for a selection of events, providing a seismotectonic constraint to the characterization of the sequence. We discuss our results in the light of the earthquake cycle, exploring the relations between seismic and aseismic processes within the context of a subduction zone with highly heterogeneous frictional properties. Finally, we present a conceptual model in which we explain the distribution and diversity of slip processes in the Ecuadorian margin, and the control factors that affect them.

\subsection{Seismotectonic context and previous studies}

The Ecuador-Colombia subduction margin has generated four large tsunamigenic megathrust earthquakes $(\mathrm{Mw}>7.5)$ in the $20^{\text {th }}$ century. In 1906, an $\mathrm{Mw} \sim 8.8$ event (the largest thus far documented offshore Ecuador) ruptured a roughly $500 \mathrm{~km}$-long segment of the margin, causing widespread damage and tsunami waves (Kanamori and McNally, 1982). Subsequent events occurred in 1942 (Mw 7.8), 1958 (Mw 7.7) and 1979 (Mw 8.2; Kanamori and McNally, 1982; Beck and Ruff, 1984), partially overlapping the rupture area of the 1906 event. This sequence of three earthquakes presented a northward migration pattern (Fig. 1), and the sum of their combined seismic moments accounts for only a fifth of the moment released by the 1906 event (Keller, 1972; Kanamori and McNally, 1982). This would imply that the 1906 event not only ruptured the other three isolated asperities simultaneously, but also broke the adjacent subduction interface which otherwise creeps during the interseismic period. 
106 The area that ruptured in 2016 had already been identified as a highly coupled region (Chlieh

107 et al., 2014; Nocquet et al., 2014), and the same asperity had allegedly been ruptured by the

108 earthquake of 1942 (Nocquet et al., 2017). In this region, the convergence rate between

109 Nazca and South America is $58 \mathrm{~mm} / \mathrm{yr}$, which is partially accommodated by the north-eastern

110 motion of the North-Andean sliver, resulting in a slip rate of $46 \mathrm{~mm} \mathrm{yr}^{-1}$ at the megathrust

111 (Chlieh et al., 2014; Nocquet et al., 2014). Also, this area is located within the northern flank

112 of the aseismic Carnegie Ridge (hereafter CR), which currently subducts beneath South

113 America between $0^{\circ}$ to $2.5^{\circ}$ lat. S.

114

115 To date, several co-seismic slip models of the 2016 earthquake have been published based on

116 a complete or partial use of teleseismic, tsunami, GPS, InSAR and regional accelerometric

117 data (e.g. Ye et al., 2016; Nocquet et al., 2017; Yoshimoto et al., 2017; Gombert et al., 2018

118 and references within). All models have in common an extension of the rupture area of

119 roughly $100 \mathrm{~km}$ along strike, a southward propagation rupture, and the presence of two

120 patches of high coseismic slip with no shallow slip near the trench. They differ, however, in

121 the maximum and average amount of slip, with maximum slip ranging from $2 \mathrm{~m}$ (Yoshimoto

122 et al., 2017) to 6-7 m (Nocquet et al., 2017; Gombert et al., 2018). These last two models are

123 very similar regarding magnitude and distribution of the co-seismic slip, and are the most

124 comprehensive up to date in terms of diversity of used datasets and methodology.

126 Previous studies using geodetic and seismological data highlight the diverse nature of slip

127 processes in the interseismic period. Font et al. (2013) produced a seismicity catalogue for a

128 13-yr period based on locations in a 3-D a priori velocity model. Vallée et al. (2013)

129 characterized a one-week-long slow slip event (SSE), accompanied by a seismic swarm, that

130 occurred in August 2010 below La Plata Island (hereafter LPI), south of the 2016 rupture. 
131 Similarly, Vaca et al. (2018) described a six-week-long SSE accompanied by a seismic

132 swarm that occurred between December 2013 and January 2014 at the northern limit of the

1332016 rupture, arguing that this area acted as a barrier for the 2016 rupture propagation

134 northwards. Finally, Segovia et al. (2018) studied the seismicity distribution during a two-

135 year experiment in the south of the region, describing the interface geometry, and associating

136 swarm-like activity to a SSE below LPI.

\section{2. Data and Methods}

\section{Earthquake rapid response deployment}

140 Following the Pedernales earthquake, an international effort involving institutions from

141 Ecuador (IG-EPN), France (Géoazur, Cerema, IRD and CNRS), the UK (U. of Liverpool)

142 and the USA (IRIS, U. of Lehigh, U. of Arizona) rapidly installed a network of 50 inland

143 stations and 10 ocean-bottom seismometers (OBS) to record for one year after the mainshock

144 (Fig. 2; Meltzer et al., 2018). This temporary deployment complemented the permanent

145 Ecuadorian network (Alvarado et al., 2018). Instruments included broadband, intermediate

146 and short period stations, in addition to some accelerometers from the Ecuadorian network,

147 all recording at a sampling rate of $100 \mathrm{~Hz}$ or higher.

\section{Data processing}

150 The continuous waveforms were collected and archived in mini-seed format. They were

151 processed using the software package SEISCOMP3 (SC3; https://www.seiscomp3.org) which

152 provides in-built capacity to detect, associate and locate seismic events including the

153 calculation of magnitudes. Although SC3 is primarily designed for real-time monitoring with

154 continuous injection of data, it can also be used in 'playback mode', that is, injecting and

155 processing the whole of the collected data at once. Parameterization of the different SC3 
modules is critical, and therefore we adopted an empirical approach in which several tests were systematically performed looking for the best set of parameters that would maximize the number of real events while minimizing the number of false detections. Control days, for which we manually detected events, were used to asses this fine-tuning process. Additionally,

160 we visually inspected the detected events and discarded false detections as well as classified

161 real events into first and second quality events according to the number and accuracy of their automatic picks (see Sup. Mat.).

164 The workflow was as follows: after injection of the continuous waveform dataset, detection 165 of arrival times was performed using a standard STA/LTA algorithm for P-phases and the 166 AIC picker implemented in SC3 for S-phases, on band-pass filtered waveforms (1-10 Hz for seismometers; 1-8 Hz for accelerometers and OBS). Subsequently, we used the SC3 module SCANLOC, which is based on the cluster-search algorithm DBSCAN (Easter et al., 1996), to associate picks and locate events. Relocation of these initial events was performed using the

170 NonLinLoc (NLL) algorithm (Lomax, 2000) configured in standard global mode. The visual quality-inspection described above was carried out on these preliminary locations. Finally, the whole set of events was relocated outside SC3 using NLL configured in regional mode (Cartesian coordinates) and a simplified velocity model taken from a newly derived 1-D velocity structure for the region (León-Ríos et al., 2017; see Sup. Mat.).

Initially, a total of 15,233 aftershocks were detected and located for the period between April 162016 to April 302017 . Visual analysis of seismic sections was performed to identify and discard false detections, spurious events, and to assess the pick quality to assemble a highquality subset of events. After this visual inspection, a total of 4,963 (33\%) events were 

discarded as false detections or spurious events (poor signal and/or too noisy). The 10,270 events left were classified into two categories according to their picks and location quality:

$1821^{\text {st }}$ quality: events with at least four P-phases and clear arrival picks - 7326 events $2^{\text {nd }}$ quality: events with pick residuals larger than $\sim 2 \mathrm{~s}$ and greater location errors - 2944

184 events

\section{Moment tensor inversions}

187 We selected aftershocks with $\mathrm{M}_{\mathrm{L}}>4.5$ to compute moment tensors from full waveform inversions, including both body and surface waves. For this we used the software ISOLA

189 (Sokos and Zaharadnik, 2008) which can handle inversions of local to regional waveforms.

190 Green functions were computed using the 1-D model produced by León-Ríos et al. (2017) and waveforms were inverted in the $10-25 \mathrm{~s}$ period range. Horizontal centroid position was kept fixed to the epicentral position from the earthquake locations, but a grid-search was performed to obtain optimal centroid depth and time. Examples of the inversion and fitting are provided in the Supplementary Material.

\section{Magnitudes}

197 Local magnitudes $\left(\mathrm{M}_{\mathrm{L}}\right)$ were calculated from maximum P-wave amplitudes on vertical

198 components. The obtained magnitudes vary between 0.7 and 6.9, with a magnitude of

199 completeness $\mathrm{Mc}=2.5$ (Sup. Mat.). In general, there is a good agreement between the

200 calculated local magnitudes $\left(\mathrm{M}_{\mathrm{L}}\right)$ and the moment magnitudes (Mw) obtained from our moment tensor inversions and those from the GCMT catalogue (Sup. Mat.). Nonetheless, we observe that for $\mathrm{Mw}>5.6$ there is an underestimation of local magnitudes, probably due to saturation of the $\mathrm{M}_{\mathrm{L}}$ scale. On the other hand, for $\mathrm{Mw}<5.6$ we observe an overestimation of 
$\mathrm{M}_{\mathrm{L}}$ by $\sim 0.3$ units. These differences are commonly observed when comparing local magnitudes with moment magnitudes (e.g. Deichmann, 2006).

\section{Residual bathymetry}

208 In order to compare the distribution of seismicity with the distribution of the incoming oceanic relief, we produced a residual bathymetry grid for the Ecuadorian margin following the ensemble averaging approach of Basset and Watts (2015), and using the higher resolution

211 GEBCO2014 grid. We calculated the average topography for a series of trench-normal

212 profiles. Then we subtracted this averaged topography from the original grid to produce an

213 elevation map where large-amplitude trench-normal variations associated with the subduction

214 zone have been removed and short-wavelength/lower amplitude structures are preserved and 215 highlighted.

\section{Spatio-temporal distribution of aftershocks}

218 Along strike, the aftershock seismicity extends beyond the coseismic rupture, over $300+\mathrm{km}$, 219 from latitude $1^{\circ} \mathrm{N}$ to at least $1.5^{\circ} \mathrm{S}$ (Fig. 3). Along the dip direction, the seismicity seems to be constrained by the coseismic rupture maximum depth, with most of the aftershocks located in

221 the upper $30 \mathrm{~km}$ and no aftershock seismicity locates deeper than the coseismic rupture 222 termination.

The most striking feature is the presence of three bands of seismicity perpendicular to the trench, and located up-dip west of the mainshock rupture area (profiles BB', CC' and DD' in

226 Fig. 3; see also Soto-Cordero et al., 2017). Interestingly, this seismicity pattern is also 227 observed in the background seismicity during the interseismic period (Font et al., 2013). The northern band (BB') extends for about $40 \mathrm{~km}$ up-dip with a width of about $10 \mathrm{~km}$. The 
central band ( $\left.\mathrm{CC}^{\prime}\right)$ is more diffuse, starting at the upper termination of the rupture area and extending $40 \mathrm{~km}$ up-dip with a width of around $20 \mathrm{~km}$. The southern band also starts at the

231 upper termination of the coseismic rupture and extends up-dip $60 \mathrm{~km}$ with a width of about

$23225 \mathrm{~km}$. Both, the southern and central bands reach the trench, whilst seismicity is more

233 diffuse close to the trench for the northern band. Although we do observe seismicity near the trench, we do not observe any extensional focal mechanism in this area that could be related to outer rise seismicity following the mainshock (e.g. Sladen and Trevisan, 2018).

Considering the location uncertainties, most of the seismicity in these three alignments occurs at the interface or within $10 \mathrm{~km}$ from it. Additionally, all large aftershocks $(\mathrm{M}>=5)$ occur outside the mainshock rupture and mostly along bands BB' and DD', located up-dip at the northern and southern limits of the co-seismic rupture, respectively. Inside the mainshock rupture area, seismicity occurs mostly between the two patches of maximum coseismic slip

241 (Figure 5, see Section 5).

To the north $\left(0.9^{\circ} \mathrm{N}\right)$, we observe a cluster of seismicity within the subduction interface below the coastline (cluster G1 in Fig. 3). Further to the east, a cluster of crustal seismicity (G2, hereafter called Esmeraldas sequence) is observed at 10-20 km depth. This group of shallow seismicity started to develop at the end of June 2016, with a burst of seismicity during July 5-8 and its largest earthquake, normal faulting $M w=4.9$, occurring on July 6, 2016 (see details in Section 4).

South of the mainshock rupture area, we observe three separate groups of seismicity. The first one is a cluster of events occurring beneath the coastline, at around latitude $0.9^{\circ} \mathrm{S}(\mathrm{G} 3)$. This cluster seems to occur on the megathrust interface, and as seen in Section 4, presents thrust focal mechanisms compatible with subduction earthquakes. The second group 
corresponds to the seismicity observed inland at around latitude $1.3^{\circ} \mathrm{S}(\mathrm{G} 4)$ which also occur

255

256

257

258

259

260

261

262

263

264

265 at the interface. The third group (G5) is located offshore, nearby LPI. This seismicity is sparsely distributed, and because of its location offshore at the southern end of the network, it is difficult to assess hypocentral depths with certainty. Nevertheless, a clue regarding the origin of this seismicity comes from previous studies which have found swarm-like seismicity and SSEs in this area (Vallee et al., 2013; Segovia et al., 2018), as well as a SSE during the early postseismic period of the 2016 mainshock (Rolandone et al., 2018). Like the trench-normal bands, these three seismicity groups had also been observed during the interseismic period (Segovia et al., 2018).

The spatio-temporal analysis of the aftershock sequence (Sup. Video) shows that during the first 24 hours after the mainshock, aftershocks start to nucleate mostly along profiles DD' and CC', and in particular between the two patches of maximum co-seismic slip. The aftershocks then extend along profiles BB' and EE'. Seismicity around LPI starts on the third day with peaks of activity on the $11^{\text {th }}$ and $12^{\text {th }}$ days after the mainshock. A last burst of seismicity in this area occurs between $1^{\text {st }}$ and $3^{\text {rd }}$ December 2016. As stated above, the shallow clustered seismicity of the Esmeraldas sequence occurs mostly during early July 2016. Finally, the seismicity observed at the interface along the profile AA' develops during December 2016.

\section{Seismotectonics and moment tensor inversions}

For the 12-month period following the Pedernales mainshock (April 162016 - April 30 2017) there are 32 moment tensors with Mw between 4.8 and 6.9 available in the GCMT catalogue (http://www.globalcmt.org/). We complemented these with 29 additional events with $\mathrm{Mw}$ between 4.1 and 5.0, for a total of 61 moment tensors (Fig. 4 and Sup. Mat.). Most of the moment tensors indicate thrust faulting at the subduction interface. No large 
aftershocks ( $\mathrm{Mw}>5$ ) occur inside the coseismic rupture area. The largest thrust aftershocks

280 occur along the seismicity bands located at the northern and southern termination of the

281 mainshock rupture. Besides these two bands dominated by thrust faulting at the interface,

282 we also observe subduction earthquakes to the south, around latitude $1^{\circ} \mathrm{S}$, and towards the

283 north by the coastline up to $1^{\circ} \mathrm{N}$. The geometry of the reverse faulting focal mechanisms is

284 similar to that of the mainshock, with an average rotational angle (Kagan angle) of $22^{\circ}$

285 relative to the mainshock's focal mechanism (inset Fig. 4).

286

287 We also observe a few normal and strike-slip events. Strike-slip events seem to be sparsely 288 located and within the subducting slab. A possible explanation for this activity could be the 289 presence of pre-existing structures in the subducting CR, reactivated by the mainshock. On 290 the other hand, two similar normal fault earthquakes, of Mw 5.1 and 4.9 respectively,

291 occurred in the marine forearc around latitude $0.3^{\circ} \mathrm{N}$, on June $1^{\text {st }} 2016$, separated by 5

292 hours. The GCMT centroid depths for these earthquakes (12 and $17 \mathrm{~km}$ depth) place them

293 close to the subduction interface, but on our own regional moment tensor inversions we

294 found the lowest waveform misfit at $5 \mathrm{~km}$ depth. Despite the depth uncertainties, a possible

295 explanation for this faulting could be given by the existence at this location of a subducted

296 seamount, previously imaged using multi-channel seismic reflection data (Marcaillou et al.,

297 2016). León-Ríos et al. (2017) hypothesize that the subduction of this structure produces an

298 anomalous extensional stress field parallel to the convergence vector, which in turn could

299 have been affected by the 2016 mainshock. In fact, Marcaillou et al. (2016) observed a

300 complex and highly fractured margin structure in this region, and argued that the absence

301 of background seismicity and low interseismic coupling here suggest that this area is 
incapable of storing sufficient elastic strain to produce large thrust earthquakes and tsunamis.

Two additional normal fault events are observed in our dataset. One is a $\mathrm{Mw}=4.4$ intermediate-depth event, most likely intra-slab, located at $0.6^{\circ} \mathrm{N}, 200 \mathrm{~km}$ east of the trench. The other is a $\mathrm{Mw}=4.9$, crustal normal fault event with a strike-slip component, belonging to the Esmeraldas sequence. Unfortunately, the uncertainties of our hypocentral locations in this area do not allow us to distinguish the fault plane from the two nodal

310 planes. On the other hand, the geological map for this area (Reyes and Michaud, 2012; Sup.

311 Mat.) shows a set of normal faults striking ESE and dipping to the $S$, which coincide with one

312 of the nodal planes of this event (strike 103, dip 42, rake -29). We suggest that crustal

313 activity on one of these faults might be responsible for the seismicity observed during the

314 Esmeraldas sequence (see also Hoskins et al., 2018). Some previous large megathrust

315 aftershock sequences, such as Maule 2010 and Tohoku 2011, have shown similar shallow

316 normal faulting at the edges of the coseismic rupture area (e.g. Kato et al., 2011; Ryder et

317 al., 2012). A similar tectonic configuration could be responsible for our normal event in the

318 Esmeraldas area, which indicates horizontal extension in the overriding plate following the

319 mainshock. Since these events are shallow, near the coast, and can produce considerable vertical displacement, they are important to consider when estimating earthquake and

321 tsunami hazard at a local scale.

The April $162016 \mathrm{Mw}=4.9$ foreshock

324 Nearly 11 minutes before the Pedernales earthquake, an event $\mathrm{M}_{\mathrm{W}}=4.9$ nucleated about 14

$325 \mathrm{~km}$ ESE of the mainshock's epicentre. We also obtained the moment tensor for this event, 
which indicates a thrust faulting mechanism, likely on the subduction interface (Fig. 4). The possibility of this earthquake to have triggered the $\mathrm{Mw}=7.8$ mainshock is worth exploring, although a dynamic or static triggering would be difficult to reconcile with the time and distance between the two events. More accurate relocations of both the foreshock and main event hypocentres, and a detailed analysis of the Coulomb stress change field, beyond the scope of this study, would be necessary to resolve this issue.

\section{Relation between coseismic rupture and aftershock distribution}

334 As a first order feature, we observe an inverse correlation between the number of aftershocks and co-seismic slip, with highs in slip associated to lows in seismicity and vice versa (e.g. at 20, 45 and $60 \mathrm{~km}$ south of the mainshock in profile N-S of Fig. 3). Figure 5 shows in detail the distribution of aftershocks and co-seismic slip. We observe that most of the large aftershocks occur outside the mainshock rupture area (defined as the $1 \mathrm{~m}$ slip contour area). When we consider all magnitudes, $28 \%$ of the aftershocks occur inside the mainshock rupture, but when we consider only events with $\mathrm{M}_{\mathrm{L}} \geq 3.5$, only $14 \%$ of aftershocks nucleate inside and, moreover, no aftershock larger than $\mathrm{M}_{\mathrm{L}}=5$ nucleated inside the mainshock rupture area.

344 Additionally, the histograms in Fig. 5 show the normalized areal distribution of co-seismic

345 slip together with the normalized frequency distribution of aftershocks inside the coseismic rupture. Accordingly, if the aftershocks occurrence were randomly distributed, the aftershock

347 frequency curve would resemble the slip frequency distribution. Instead, we observe that

348 aftershocks tend to concentrate at intermediate levels of coseismic slip (2-3.5 m),

349 particularly in areas of large slip gradient, such as in between the two patches of coseismic

350 slip maxima. On the other hand, areas of low coseismic slip $(<2 \mathrm{~m})$ present less seismicity 
than expected, whilst areas of high coseismic slip $(>4.5 \mathrm{~m})$ seem to present a random distribution of aftershocks (histogram Fig. 5a), although when we consider only events with $\mathrm{M}_{\mathrm{L}} \geq 3.5$, there is a lack of aftershocks compared to a random distribution (histogram Fig. $5 b$ ).

If we look at the aftershock density, we observe that in terms of number of events, the highest density is located inside the mainshock rupture area, in between the two patches of maximum coseismic slip (Fig. 6a). If instead we look at the seismic moment density (Fig. 6b), we observe that inside the mainshock rupture area the moment density is relatively low $\left(<1 \mathrm{e}^{17} \mathrm{~N}\right.$ $\left.\mathrm{m} / 0.1^{\circ} \mathrm{x} 0.1^{\circ}\right)$. On the other hand, high moment density $\left(>1 \mathrm{e}^{18} \mathrm{~N} \mathrm{~m} / 0.1^{\circ} \mathrm{x} 0.1^{\circ}\right)$ is observed outside the mainshock rupture, along the three trench-normal seismicity bands and particularly nearby the coastline at latitude $0.5^{\circ} \mathrm{N}$, due to the occurrence here of the largest aftershock of the sequence ( $\mathrm{Mw}=6.9$, thrust faulting).

\section{Relation between seismic and aseismic processes}

We compare the temporal evolution of the aftershock sequence with that of the geodetic afterslip during the first 30 days following the mainshock. Following Rolandone et al. (2018), we consider the afterslip and aftershocks as three discrete patches (North, South and LPI; see Fig. 3 and Sup. Mat) according to their spatial distribution, and analyse them separately (Fig. 7). Cumulative seismicity (red curve) for the northern and southern patches show an Omoritype decay in which a steep slope is observed immediately after the mainshock, followed by a deceleration after the first week of aftershocks. On the other hand, the LPI patch shows a rather slow start in aftershocks generation, and then an increase from day 8 until day $\sim 20$ when it decreases again. The different behaviour in the LPI patch could be explained because this area hosted a slow slip event associated to seismicity during this period (Rolandone et al., 2018). 
We observe for all three patches that the curve for cumulative number of earthquakes closely follows that of the afterslip cumulative moment release, implying a linear relationship between both processes. In fact, if we assume that both afterslip and aftershocks cumulative distributions present an exponential behaviour, their curves should resemble a straight-line in a semi-logarithmic plot, as seen in the right panels of Fig. 7, which also show both curves present similar slopes (segmented lines). Leaving the LPI patch aside, the linear relation between cumulative aftershocks and afterslip release is remarkable.

Furthermore, for each of the patches we observe that after 30 days of postseismic activity, the total cumulative moment released by the aftershocks represents about $10 \%$ of the cumulative moment released by the afterslip, indicating that most of the postseismic deformation is aseismic (Sup. Mat).

Additionally, we explore the spatial dependency between afterslip and aftershocks. As seen from the geographic distribution of seismicity outside the mainshock rupture area, aftershocks are spatially associated with afterslip, particularly in the area of the trench-normal bands and around LPI (Fig. 3). Figure 8 shows the temporal evolution of seismicity as a function of along-strike distance from the mainshock epicentre, clearly showing a log-time expansion of the aftershocks. A similar behaviour is seen for the along-dip direction (Sup. Mat). These observations are consistent with previous studies (e.g. Frank et al., 2017), and numerical modelling (e.g. Ariyoshi et al., 2007; Perfettini et al., 2018) which suggest that this type of semilogarithmic migration is indicative of afterslip-driven aftershock activity. 


\section{Discussion}

\subsection{Where do aftershocks occur?}

403 The largest aftershocks occur outside the mainshock rupture area. This finding is in

404 agreement with previous studies which have found that regions of high coseismic slip are

405 mostly devoid of large aftershocks, whilst post-seismic seismicity tends to concentrate at the

406 edges of the coseismic rupture (e.g. Das and Henry, 2003; Asano et al., 2011; Rietbrock et

407 al., 2012; Agurto et al., 2012; Frank at al., 2017; Wetzler et al., 2018). For the $2010 \mathrm{Mw}=8.8$

408 Maule earthquake, Agurto et al. (2012) also found that aftershocks concentrated at

409 intermediate levels of coseismic slip, with areas of low and large coseismic slip lacking in

410 aftershocks. Therefore, this could be a common feature for large megathrust earthquakes with

411 a heterogeneous distribution of coseismic slip.

412

413 Additionally, a large number of aftershocks do occur within the co-seismic rupture area,

414 although presenting low magnitudes. The fact that aftershocks nucleate inside the mainshock

415 rupture area indicates that the accumulated strain energy within the fault is not totally

416 released during the mainshock, or at least that this release is not homogeneously distributed

417 along the megathrust rupture. Attempting to investigate this issue, Yabe and Ide (2018)

418 produced quasi-dynamic numerical simulations in which they replicate several megathrust

419 frictional scenarios and mainshock ruptures with their respective aftershock sequences. They

420 observed aftershocks around and within the mainshock rupture area for cases in which

421 frictional heterogeneity varies significantly along the fault. On the other hand, aftershocks were not produced when frictional heterogeneities along the fault were small. Similarly, the fact that for the Pedernales sequence we observe the highest density of aftershocks within the

424 mainshock rupture area, might be indicative of the highly heterogeneous distribution of

425 frictional properties along the northern Ecuador megathrust. 
When we account for location uncertainties, the low-magnitude seismicity located within the

427

428

430

431

432

433

434

435

436

437

438

439

440

441

442

443

444

445

446

447

448

449

450 co-seismic rupture area seems to occur distributed within the seismogenic volume and not only at the megathrust interface (Fig. 3). This volume represents the off-fault damage zone produced by successive megathrust ruptures, and it usually concentrates a diversity of aftershocks focal mechanisms in structures re-activated by the mainshock (e.g. Asano et al., 2011; Agurto et al., 2012).

\subsection{What controls the evolution of the aftershock seismicity?}

The temporal linear dependency between afterslip and aftershocks shown here (Fig. 7) suggests a causative time-based relationship between these two processes, and therefore the temporal distribution of aftershocks associated to patches of afterslip would be modulated by the stressing rate associated with afterslip (e.g. Perfettini and Avouac, 2004; Hsu et al., 2006).

Additionally, the semi-logarithmic migration of aftershocks both along strike and dip (Fig. 8) suggests that afterslip also controls the spatial extension and migration speed of aftershocks (e.g. Frank et al., 2017; Perfettini et al., 2018). We notice that the origin of the two red lines indicating the propagation front in Fig. 8 is not located at the epicentre but approximately 40 $\mathrm{km}$ south of it, in the area where most of the aftershock seismicity take place during the first 24 hours following the mainshock (Section 3). This corresponds to the centre of the coseismic rupture, and therefore we hypothesize that the expansion of aftershocks is initiated at this point, subsequently propagating outwards.

Another explanation for the observed aftershocks expansion could be related to fluid diffusion. Nevertheless, in such a case we would observe that the distance D associated with 
the migration front of the seismicity is related to time $t$ as $\mathrm{D} \sim \operatorname{sqrt}(\mathrm{t}) \mathrm{c}$, where $\mathrm{c}$ is the hydraulic diffusivity coefficient (Wang, 2000). This is unlike our observations, in which we see that $\mathrm{D} \sim \log (\mathrm{t})$.

Finally, we notice that a similar relationship between seismic and aseismic processes in our study area has also been described during the interseismic period (Vallée et al., 2013; Rolandone et al., 2018; Segovia et al., 2018; Vaca et al., 2018). These previous studies describe seismic swarms associated to SSEs in the offshore area in front of Punta Galera (lat. $\sim 0.7^{\circ} \mathrm{N}$; Vaca et al., 2018), and around LPI (Vallée et al., 2013; Segovia et al., 2018). A similar SSE around LPI occurred during the postseismic period of the 2016 Pedernales earthquake, also associated with seismicity (Rolandone et al., 2018). Therefore, it seems that the close spatio-temporal correlation between seismic and aseismic processes in this region is persistent during the whole of the earthquake cycle.

\subsection{Persistent seismicity patterns over the earthquake cycle}

Aseismic slip seems to modulate the rate and spatio-temporal expansion of the aftershock seismicity. But why do these slip processes occur where they occur in the first place? In our study area, the presence of persistent spatial seismicity patterns over the earthquake cycle, such as the three trench-normal bands and the seismicity south of the mainshock rupture area

470 (Font et al., 2013), suggest that earthquake nucleation in these areas is somehow controlled by long-lived structural features. We also notice that the bands are dominated by thrust events as opposed to parallel to the convergence vector. 
475 To our knowledge, no other subduction zone presents this type of permanent seismicity 476 pattern transcending the earthquake cycle. Observations in other tectonic settings such as

477 Parkfield, in the San Andreas fault, show sub-horizontal alignments of seismicity along the 478 fault plane that also persist through many seismic cycles. Because of its geometry and the 479 motion of the fault, it has been proposed that this seismic activity is related to rheological 480 transitions within the fault zone and/or stress concentrations between locked and creeping areas (e.g. Waldhauser et al., 2004). Nonetheless, invoking rheological transitions in our area is a less plausible hypothesis to explain our observations, mainly because the seismicity within the bands lacks any clear depth-dependency.

One additional hypothesis is that the interface frictional properties in these regions of high seismicity are somehow different than in the rest of the area. In this sense, the interseismic coupling map for our study region (Fig. 1) shows that the general area of the bands is only slightly coupled $(<40 \%)$, but the model lacks the resolution to see any difference along strike, between areas with seismicity (bands) and areas without.

490

\subsection{Influence of the subducting seafloor relief}

492 Previous studies have proposed an along-strike segmentation of the Ecuadorian margin in which large subduction earthquakes only occur north of the CR, which acts as a barrier to the southward propagation of megathrust ruptures (e.g. Collot et al., 2004). More generally, it has been proposed that rugged subducting seafloor, as in the case of seamounts and ridges, give rise to heterogeneous stresses, promoting creep as expressed in transient events of various spatial and temporal scales, accompanied with small and medium-sized earthquakes (Wang and Bilek, 2014). Bassett and Watts (2015) produced a compilation of residual bathymetric anomalies for several subduction zones of the world, and found that regions with subducted 
seamounts were correlated to reduced levels of megathrust activity, suggesting that these areas are mostly associated with small earthquakes and creep rather than with large megathrust events. Furthermore, they argue that larger bathymetric features, such as aseismic ridges, exhibit seafloor roughness over a larger scale than subducted seamounts, presenting widths comparable to the rupture length of large $(\mathrm{Mw} \sim 7)$ megathrust earthquakes. They observe that the maximum roughness is located at the flanks of the ridges, which often serve as barriers of rupture propagation. For the Ecuador subduction zone, some authors observed that the northern flank of the CR has acted as a barrier against the southward propagation of the 1906 and 1942 earthquakes (Kelleher, 1972; Collot et al., 2004).

510 Following the ensemble averaging approach of Bassett and Watts (2015), and benefiting from 511 combined high resolution datasets, we produced improved maps of residual bathymetry for

512 the Ecuadorian margin. We compared the spatial distribution of these anomalies with the 513 distribution of the seismic and aseismic processes before and after the Pedernales earthquake

514 (Fig. 9). Landward from the trench, the down-dip limit of the area with high residual

515 bathymetry $(>2 \mathrm{~km})$ coincides with the up-dip limit of the Pedernales earthquake rupture area. Bassett and Watts (2015) notice that this limit coincide with the continental slope break,

517 and suggest that the slope break corresponds to the updip limit of the seismogenic zone, and

518 that the outer portion of the plate interface, below the steep continental slope, is

519 weak/conditionally stable and would slip aseismically. Furthermore, we notice that both the 5201942 and the 2016 epicentres are located nearby this limit, with the 2016 mainshock rupture area itself extending down-dip from this limit, within an area of smoother residual bathymetry. We also notice that the trench-normal bands of seismicity observed during the interseismic and post-seismic periods occur in areas of higher gradient and residual

524 bathymetry. In particular, the seismicity band DD', which marks the southern boundary of 
the Pedernales rupture zone, is in front of the highest bathymetric and gravity anomaly, which correspond to the thickest part of the CR crust ( $20 \mathrm{~km}$; Collot et al., 2004; Sallarès et al., 2005). Lastly, both the SSEs observed during the interseismic period, and the afterslip patches observed during the post-seismic period occur in areas dominated by high residual bathymetry due to the subduction of the CR (Fig. 9).

We summarize our observations in an interpretative figure (Fig. 10) in which we suggest that the Ecuadorian margin hosts a bimodal slip mode mechanically controlled by the distribution of the subducting oceanic relief. The bimodal slip mode produces seismic and aseismic slip processes, and is present both along-strike and along-dip. In the area where the CR subducts beneath the margin (latitude $0^{\circ}$ to $\sim 2.5^{\circ} \mathrm{S}$ ), particularly in the region containing a high residual bathymetry ( $>2 \mathrm{~km}$, from the trench until $\sim 90 \mathrm{~km}$ landward; Zone A in Fig. 10), the overall ISC is low $(<40 \%)$, and the subduction slip mode is dominated by creep and small to medium-sized earthquakes $(\mathrm{Mw}<6)$, swarm-like seismicity and SSEs during the interseismic phase, and aseismic afterslip during the postseismic period. Down-dip of this limit (i.e. over $90 \mathrm{~km}$ horizontally from the trench, down to the maximum seismogenic depth; Zone B), the ISC is higher ( $>40 \%)$ and the slip mode is dominated by large subduction earthquakes $(\mathrm{Mw}>7)$ as in the case of the 2016 Pedernales Earthquake and similar past ruptures. Along strike to the north of the ridge flank, away from the area of influence of the CR (Zone C), the overall ISC is high up to the trench, and megathrust earthquake ruptures could reach the trench, as allegedly was the case for the 1906 earthquake and possibly the 1979 earthquake. Therefore, Zone A presents an overall stable regime (velocity-strengthening) whilst Zones B and $\mathrm{C}$ are unstable/conditionally stable (velocity-weakening). Thus, the area of high residual bathymetry $(>2 \mathrm{~km}$ ) would act as a barrier to up-dip (trench-normal) propagation of 
megathrust ruptures, whilst the lateral flanks of the ridge would act as barriers to along-strike

550 (trench-parallel) rupture propagation.

551

552

\section{Conclusion}

553 We characterised the aftershock seismicity occurring in the Ecuadorian margin over one year

554 following the $2016 \mathrm{Mw}=7.8$ Pedernales earthquake. More than 10,000 events were detected and located, with magnitudes up to 6.9. Most of the seismicity results from interplate thrust faulting but we also observe a few normal and strike-slip mechanisms. Within the mainshock rupture area, seismicity concentrates in regions of intermediate coseismic slip, particularly in between the two patches of slip maxima. Outside the rupture area, seismicity extends for more than $300 \mathrm{~km}$ along strike. The most striking feature is the presence of three seismicity bands, perpendicular to the trench, which are also observed during the interseismic period.

562 We observe a linear dependency between the temporal evolution of afterslip and number of

563 aftershocks, confirming previous results (Rolandone et al., 2018). Additionally, aftershocks

564 present a temporal semi-logarithmic expansion along the strike and dip directions, which

565 further suggest their spatio-temporal occurrence is regulated by afterslip. A comparison of the

566 distribution of seismic and aseismic slip processes with the distribution of bathymetric

567 anomalies reveals that slip in the area seems to be controlled by the subduction of oceanic

568 plate roughness. To explain our observations, we propose a conceptual model in which the

569 Ecuadorian margin presents a bimodal slip mode mechanically controlled by the subduction

570 of a rough oceanic relief. In this sense, the flanks of the CR act as a barrier to the propagation

571 of megathrust ruptures, both up-dip and along-strike. On the other hand, the area of

572 maximum influence of the CR (residual bathymetry $>2 \mathrm{~km}$ ) is characterized by small

573 magnitude earthquakes $(\mathrm{Mw}<6)$, aseismic slip, repeating events and earthquake swarms. 


\section{Acknowledgments}

The rapid deployment of the seismic array after the Pedernales earthquake was supported by IG-EPN and IRD in the frame of the International Joint Laboratory "Earthquakes and Volcanoes in the Northern Andes", INSU-CNRS, the University of Liverpool, Lehigh University and the University of Arizona. The US Seismic Rapid Response deployment was supported by the NSF RAPID Program Award EAR-1642498 and by the PASSCAL facility of the Incorporated Research Institutions for Seismology (IRIS) through the PASSCAL Instrument Center at New Mexico Tech with support from the National Science Foundation under Cooperative Agreement EAR-1261681 and by the Department of Energy National Nuclear Security Administration. The OBS were deployed from R/V "ORION" provided by INOCAR (May 2016) and recovered from Coast Guard vessel "LG-52" in harsh sea conditions thanks to Davide Oregioni and Deny Malengros (Géoazur). A special thank to Comandante Andres Pazmiño (INOCAR) and Esmeraldas Coast-Guard Captain Patricio Estupinian for securing shiptime and providing invaluable help to prepare OBS on-land. We are also grateful to IRD for supporting the postdoc grant of HAD and project REMAKE (ANR-15-CE04-0004) for supporting the processing and interpretation of the data. HAD acknowledges fruitful discussions with I. Manighetti and C. Twardzik. Figures were compiled using GMT software (Wessel and Smith, 1998).

\section{References}

Agurto, H., Rietbrock, A., Ryder, I., Miller, M., 2012. Seismic-afterslip characterization of the $2010 \mathrm{Mw}$ 8.8 Maule, Chile, earthquake based on moment tensor inversion. Geophys. Res. Lett. 39. https://doi.org/10.1029/2012GL053434

Alvarado, A., Ruiz, M., Mothes, P., Yepes, H., Segovia, M., Vaca, M., Ramos, C., Enríquez, W., Ponce, G., Jarrín, P., Aguilar, J., Acero, W., Vaca, S., Singaucho, J.C., Pacheco, D., Córdova, A., 2018. Seismic, Volcanic, and Geodetic Networks in Ecuador: Building Capacity for Monitoring and Research. Seismol. Res. Lett. 89. https://doi.org/10.1785/0220170229

Ariyoshi, K., Matsuzawa, T., Hasegawa, A., 2007. The key frictional parameters controlling spatial variations in the speed of postseismic-slip propagation on a subduction plate boundary. Earth Planet. Sci. Lett. 256, 136-146. https://doi.org/10.1016/j.eps1.2007.01.019

Asano, Y., Saito, T., Ito, Y., Shiomi, K., Hirose, H., Matsumoto, T., Aoi, S., Hori, S., Sekiguchi, S., 2011. Spatial distribution and focal mechanisms of aftershocks of the 2011 off the Pacific coast of Tohoku Earthquake. Earth, Planets Sp. 63, 669-673. https://doi.org/10.5047/eps.2011.06.016

Basset, D., Watts, A., 2015. Gravity anomalies, crustal structure, and seismicity at subduction zones: 1 . Seafloor roughness and subducting relief. Geochemistry Geophys. Geosystems 16, 1508-1540. https://doi.org/10.1002/ 2014GC005684

Beck, S.L., Ruff, L.J., 1984. The rupture process of the great 1979 Colombia earthquake: evidence for the asperity model. J. Geophys. Res. 89, 9281-9291. https://doi.org/10.1029/JB089iB11p09281 
Beck, S.L., Rietbrock, A., Tilmann, F., Barrientos, S., Meltzer, A.S., Oncken, O., Bataille, K., Roeker, S., Vilotte, J.-P., Russo, R.M., 2014. Advancing Subduction Zone Science After a Big Quake Access and Use of Data Lead to Innovative Ways. EOS, Trans. Am. Geophys. Union 95, 193-194.

Bilek, S.L., Lay, T., 2018. Subduction zone megathrust earthquakes. Geosphere 14, 1-33. https://doi.org/10.1130/GES01608.1

Chlieh, M., Mothes, P.A., Nocquet, J.M., Jarrin, P., Charvis, P., Cisneros, D., Font, Y., Collot, J.Y., Villegas-Lanza, J.C., Rolandone, F., Vallée, M., Regnier, M., Segovia, M., Martin, X., Yepes, H., 2014. Distribution of discrete seismic asperities and aseismic slip along the Ecuadorian megathrust. Earth Planet. Sci. Lett. 400, 292-301. https://doi.org/10.1016/j.epsl.2014.05.027

Collot, J.Y., Marcaillou, B., Sage, F., Michaud, F., Agudelo, W., Charvis, P., Graindorge, D., Gutscher, M.A., Spence, G., 2004. Are rupture zone limits of great subduction earthquakes controlled by upper plate structures? Evidence from multichannel seismic reflection data acquired across the northern Ecuador-southwest Colombia margin. J. Geophys. Res. Solid Earth 109, 1-14. https://doi.org/10.1029/2004JB003060

Das, S., Henry, C., 2003. Spatial relation between main earthquake slip and its aftershock distribution. Rev. Geophys. 41. https://doi.org/10.1029/2002RG000119

Deichmann, N., 2006. Local Magnitude, a Moment Revisited. Bull. Seismol. Soc. Am. 96, 1267-1277. https://doi.org/10.1785/0120050115

Ester, M., Kriegel, H., Sander, J., Xu, X., 1996. A Density-Based Algorithm for Discovering Clusters in Large Spatial Databases with Noise. KDD 96, 226-231.

Font, Y., Segovia, M., Vaca, S., Theunissen, T., 2013. Seismicity patterns along the ecuadorian subduction zone: New constraints from earthquake location in a 3-D a priori velocity model. Geophys. J. Int. 193, 263-286. https://doi.org/10.1093/gji/ggs083

Frank, W.B., Poli, P., Perfettini, H., 2017. Mapping the rheology of the Central Chile subduction zone with aftershocks. Geophys. Res. Lett. 44, 5374-5382. https://doi.org/10.1002/2016GL072288

Freed, A.M., 2005. Earthquake Triggering By Static, Dynamic, and Postseismic Stress Transfer. Annu. Rev. Earth Planet. Sci. 33, 335-367. https://doi.org/10.1146/annurev.earth.33.092203.122505

Gombert, B., Duputel, Z., Jolivet, R., Simons, M., Jiang, J., Liang, C., Fielding, E.J., Rivera, L., 2018. Strain budget of the Ecuador-Colombia subduction zone: A stochastic view. Earth Planet. Sci. Lett. 498, 288-299. https://doi.org/10.1016/j.eps1.2018.06.046

Hardebeck, J.L., 2012. Coseismic and postseismic stress rotations due to great subduction zone earthquakes. Geophys. Res. Lett. 39, 1-6. https://doi.org/10.1029/2012GL053438

Hoskins, M., Meltzer, A., Soto-Cordero, L., Stachnik, J., Beck, S., Lynner, C., Ruiz., M.C., Alvarado, A., Hernandez, S., Charvis, P., Font, Y., Nocquet, J.M., Rolandone, F., 

Modes in Postseismic Deformation North of the April 16, $2016 \mathrm{M}_{\mathrm{w}} 7.8$ Pedernales, Ecuador Megathrust Earthquake. Abstract T43E-0444 2018 Fall Meeting, AGU, Washington, D.C., 10-14 Dec.

Hsu, Y.J., Simons, M., Avouac, J.P., Galeteka, J., Sieh, K., Chlieh, M., Natawidjaja, D., Prawirodirdjo, L., Bock, Y., 2006. Frictional afterslip following the 2005 Nias-Simeulue earthquake, Sumatra. Science (80-. ). 312, 1921-1926. https://doi.org/10.1126/science.1126960

Kanamori, H., McNally, K.C., 1982. Variable rupture mode of the subduction zone along the Ecuador-Colombia coast. Bull. Seismol. Soc. Am. 72, 1241-1253.

Kato, A., Sakai, S., Obara, K., 2011. A normal-faulting seismic sequence triggered by the 2011 off the Pacific coast of Tohoku Earthquake: Wholesale stress regime changes in the upper plate. Earth, Planets Sp. 63, 745-748. https://doi.org/10.5047/eps.2011.06.014

Kelleher, J.A.., 1972. Rupture zones of large South American earthquakes and some predictions. J. Geophys. Res. 77, 2087. https://doi.org/10.1029/JB077i011p02087

Leon-Rios, S., Aguiar, A.L., Bie, L., Edwards, B., Velasco, A.J.F., Holt, J., Garth, T., González, P.J., Rietbrock, A., Agurto-Detzel, H., Charvis, P., Font, Y., Nocquet, J.M., Regnier, M., Renouard, A., Mercerat, D., Permoud, M., Beck., S., Meltzer., A., SotoCordero., L., Alvarado., A., Perrault, M., Ruiz, M. and Santo, J., 2017. The $2016 \mathrm{Mw}$ 7.8 Pedernales, Ecuador earthquake: Minimum 1D Velocity Model and Regional Moment Tensors Based on the Aftershock Sequence. Abstract S53C-2352 presented at 2017 Fall Meeting, $A G U$, New Orleans, LA, 11-15 Dec.

Lomax, A., Virieux, J., Volant, P., Berge-Thierry, C., 2000. Probabilistic Earthquake Location in 3D and Layered Models, in: Thurber, C.H., Rabinowitz, N. (Eds.), Advances in Seismic Event Location. Kluwer Academic Publishers, pp. 101-134. https://doi.org/10.1007/978-94-015-9536-0_5

Marcaillou, B., Collot, J.Y., Ribodetti, A., d'Acremont, E., Mahamat, A.A., Alvarado, A., 2016. Seamount subduction at the North-Ecuadorian convergent margin: Effects on structures, inter-seismic coupling and seismogenesis. Earth Planet. Sci. Lett. 433, 146158. https://doi.org/10.1016/j.eps1.2015.10.043

Meltzer A., S. Beck, M. Ruiz, M. Hoskins, L. Soto-Cordero, J.C. Stachnik, C. Lynner, R. Porritt, D. Portner, A. Alvarado, S. Hernandez, H. Yepes, P. Charvis, Y. Font, M. Regnier, A. Rietbrock, 2018. The 2016 Mw 7.8 Pedernales Earthquake, Ecuador: RAPID Response Deployment. Submitted.

Nocquet, J.M., Jarrin, P., Vallée, M., Mothes, P.A., Grandin, R., Rolandone, F., Delouis, B., Yepes, H., Font, Y., Fuentes, D., Régnier, M., Laurendeau, A., Cisneros, D., Hernandez, S., Sladen, A., Singaucho, J.C., Mora, H., Gomez, J., Montes, L., Charvis, P., 2017. Supercycle at the Ecuadorian subduction zone revealed after the 2016 Pedernales earthquake. Nat. Geosci. 10, 145-149. https://doi.org/10.1038/ngeo2864 
Nocquet, J.M., Villegas-Lanza, J.C., Chlieh, M., Mothes, P.A., Rolandone, F., Jarrin, P., Cisneros, D., Alvarado, A., Audin, L., Bondoux, F., Martin, X., Font, Y., Régnier, M., Vallée, M., Tran, T., Beauval, C., Maguiña Mendoza, J.M., Martinez, W., Tavera, H., Yepes, H., 2014. Motion of continental slivers and creeping subduction in the northern Andes. Nat. Geosci. 7, 287-291. https://doi.org/10.1038/ngeo2099

Perfettini, H., Avouac, J., 2004. Postseismic relaxation driven by brittle creep: A possible mechanism to reconcile geodetic measurements and the decay rate of aftershocks, application to the Chi-Chi earthquake, Taiwan 109, 1-15. https://doi.org/10.1029/2003JB002488

Perfettini, H., Frank, W.B., Marsan, D., Bouchon, M., 2018. A Model of Aftershock Migration Driven by Afterslip. Geophys. Res. Lett. 45, 2283-2293. https://doi.org/10.1002/2017GL076287

Reyes, P., Michaud, F., 2012. Mapa Geológico de la Margen Costera Ecuatoriana (1:50000). EP PetroEcuador, Quito, Ecuador.

Rietbrock, A., Ryder, I., Hayes, G., Haberland, C., Comte, D., Roecker, S., Lyon-Caen, H., 2012. Aftershock seismicity of the 2010 Maule $\mathrm{Mw}=8.8$, Chile, earthquake: Correlation between co-seismic slip models and aftershock distribution? Geophys. Res. Lett. 39, 26. https://doi.org/10.1029/2012GL051308

Rolandone, F., Nocquet, J.M., Mothes, P.A., Jarrin, P., Vallée, M., Cubas, N., Hernandez, S., Plain, M., Vaca, S., Font, Y., 2018. Areas prone to slow slip events impede earthquake rupture propagation and promote afterslip. Sci. Adv. 4, 2-9. https://doi.org/10.1126/sciadv.aao6596

Ryder, I., Rietbrock, A., Kelson, K., Bürgmann, R., Floyd, M., Socquet, A., Vigny, C., Carrizo, D., 2012. Large extensional aftershocks in the continental forearc triggered by the 2010 Maule earthquake, Chile. Geophys. J. Int. 188, 879-890. https://doi.org/10.1111/j.1365-246X.2011.05321.x

Sallarès, V., Charvis, P., Flueh, E.R., Bialas, J., Party, S.S., 2005. Seismic structure of the Carnegie ridge and the nature of the Galápagos ho. Geophys. J. Int. 161, 763-788. https://doi.org/10.1111/j.1365-246X.2005.02592.x

Segovia, M., Font, Y., Régnier, M., Charvis, P., Galve, A., 2018. Seismicity Distribution Near a Subducting Seamount in the Central Ecuadorian Subduction Zone, Space-Time Relation to a Slow-Slip Event. Tectonics 37, 2106-2123. https://doi.org/10.1029/2017TC004771

Sladen, A., Trevisan, J., 2018. Shallow megathrust earthquake ruptures betrayed by their outer-trench aftershocks signature. Earth Planet. Sci. Lett. 483, 105-113. https://doi.org/10.1016/j.epsl.2017.12.006

Sokos, E.N., Zahradnik, J., 2008. ISOLA a Fortran code and a Matlab GUI to perform multiple-point source inversion of seismic data. Comput. Geosci. 34, 967-977. https://doi.org/10.1016/j.cageo.2007.07.005 
Soto-Cordero L., J. Nealy, A. Meltzer, H. Agurto-Detzel. A. Alvarado, S. Beck, H. Benz, E. Bergman, P. Charvis, Y. Font, G. Hayes, S. Hernandez, M. Hoskins, S. Leon Rios, C. Lynner, M. Regnier, A. Rietbrock, M. Ruiz, J. C. Stachnik, W. Yeck, 2017, New insights on co- and post-seismic deformation and slip behavior associated with the Mw7.8 2016 Pedernales, Ecuador earthquake and its aftershock sequence", Abstract S53C-0715 presented at 2017 Fall Meeting, $A G U$, New Orleans, LA, 11-15 Dec

Stein, R.S., 1999. The role of stress transfer in earthquake occurrence : Abstract : Nature. Nature 402, 605-609.

Vaca, S., Vallée, M., Nocquet, J.M., Battaglia, J., Régnier, M., 2018. Recurrent slow slip events as a barrier to the northward rupture propagation of the 2016 Pedernales earthquake (Central Ecuador). Tectonophysics 724-725, 80-92. https://doi.org/10.1016/j.tecto.2017.12.012

Vallée, M., Nocquet, J.M., Battaglia, J., Font, Y., Segovia, M., Régnier, M., Mothes, P., Jarrin, P., Cisneros, D., Vaca, S., Yepes, H., Martin, X., Béthoux, N., Chlieh, M., 2013. Intense interface seismicity triggered by a shallow slow slip event in the Central Ecuador subduction zone. J. Geophys. Res. Solid Earth 118, 2965-2981. https://doi.org/10.1002/jgrb.50216

Waldhauser, F., Ellsworth, W.L., Schaff, D.P., Cole, A., 2004. Streaks, multiplets, and holes: High-resolution spatio-temporal behavior of Parkfield seismicity. Geophys. Res. Lett. 31, L18608. https://doi.org/10.1029/2004GL020649

Wang, H.F., 2000. Theory of Linear Poroelasticity. Princeton Univ. Press., Princeton, N.J.

Wang, K., Bilek, S.L., 2014. Invited review paper: Fault creep caused by subduction of rough seafloor relief. Tectonophysics 610, 1-24. https://doi.org/10.1016/j.tecto.2013.11.024

Wessel, P., Smith, W.H.F., 1998. New, improved version of generic mapping tools released. Eos, Trans. Am. Geophys. Union 79, 579-579. https://doi.org/10.1029/98EO00426

Wetzler, N., Lay, T., Brodsky, E.E., Kanamori, H., 2018. Systematic deficiency of aftershocks in areas of high coseismic slip for large subduction zone earthquakes. Sci. Adv. 4, 1-9. https://doi.org/10.1126/sciadv.aao3225

Yabe, S., Ide, S., 2018. Why Do Aftershocks Occur Within the Rupture Area of a Large Earthquake? Geophys. Res. Lett. 45, 4780-4787. https://doi.org/10.1029/2018GL077843

Ye, L., Kanamori, H., Avouac, J.P., Li, L., Cheung, K.F., Lay, T., 2016. The 16 April 2016, MW7.8 (MS7.5) Ecuador earthquake: A quasi-repeat of the 1942 MS7.5 earthquake and partial re-rupture of the 1906 MS8.6 Colombia-Ecuador earthquake. Earth Planet. Sci. Lett. 454, 248-258. https://doi.org/10.1016/j.eps1.2016.09.006

Yoshimoto, M., Kumagai, H., Acero, W., Ponce, G., Vásconez, F., Arrais, S., Ruiz, M., Alvarado, A., Pedraza García, P., Dionicio, V., Chamorro, O., Maeda, Y., Nakano, M., 2017. Depth-dependent rupture mode along the Ecuador-Colombia subduction zone. Geophys. Res. Lett. 44, 2203-2210. https://doi.org/10.1002/2016GL071929 
Figure 1. Interseismic coupling (Nocquet et al., 2014) and main seismotectonic features. White stars and solid white lines show epicentres and approximate rupture areas of past megathrust earthquakes respectively (Kanamori and McNally, 1982; Mendoza and Dewey, 1984). Yellow star shows epicentre of 2016 mainshock together with its GCMT focal mechanism. Blue contour shows rupture area of 2016 event (Nocquet et al., 2017). Black contours show depth of subduction interface every $10 \mathrm{~km}$ (Hayes, 2012). Segmented black line indicates the Dolores-Guayaquil Fault Zone (Collot et al., 2002). Convergence NAZ/NAS from Chlieh et al. (2014). NAZ Nazca Plate, NAS North Andean Sliver, SAM South American Plate. 

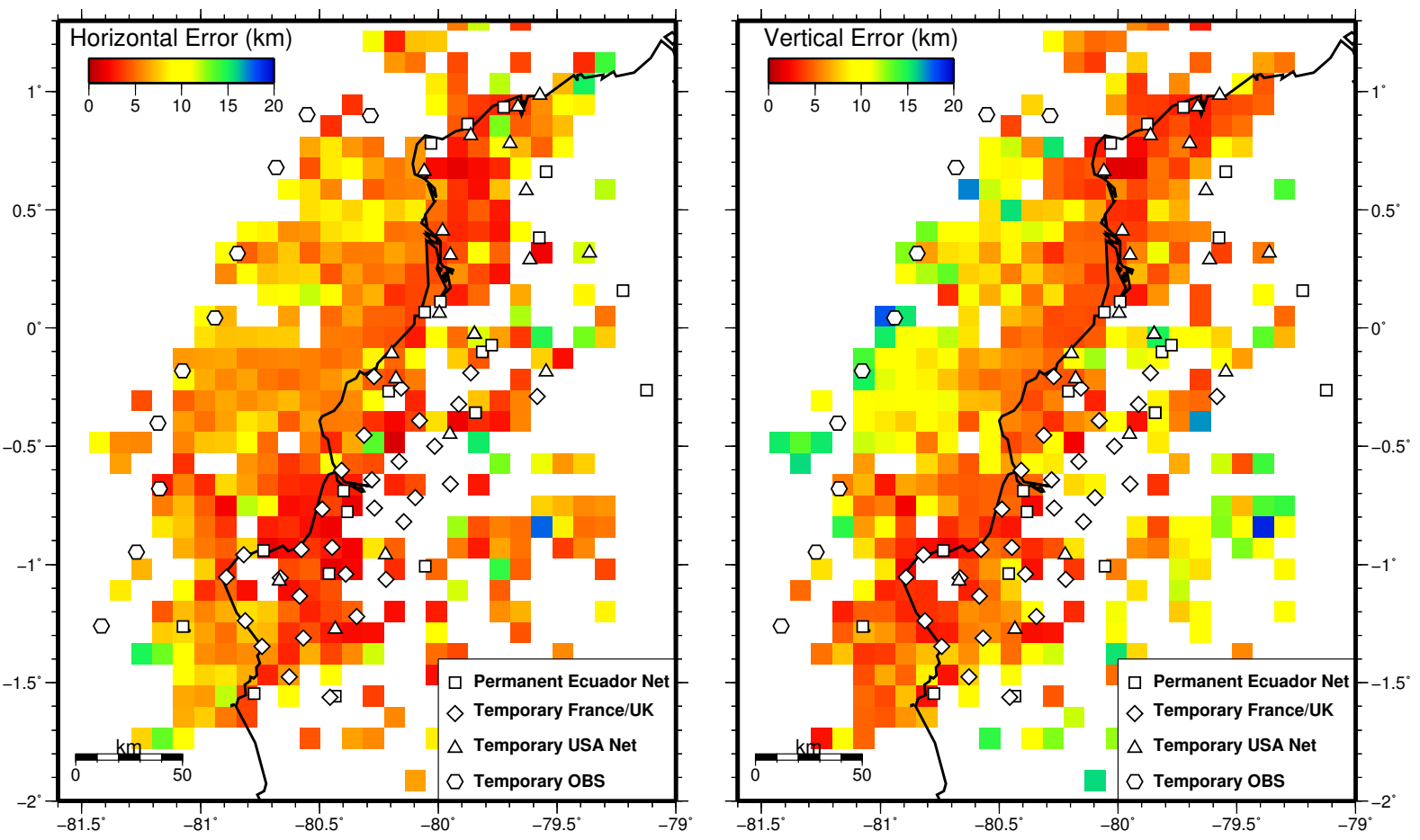

Figure 2. Seismic network and average location errors (68\% confidence) for events with confidence ellipse semi-axes less than $20 \mathrm{~km}$ (50\% of total events). Left: average horizontal

802 error; Right: average vertical error.

803

804

805

806

807

808

809

810

811

812

813 

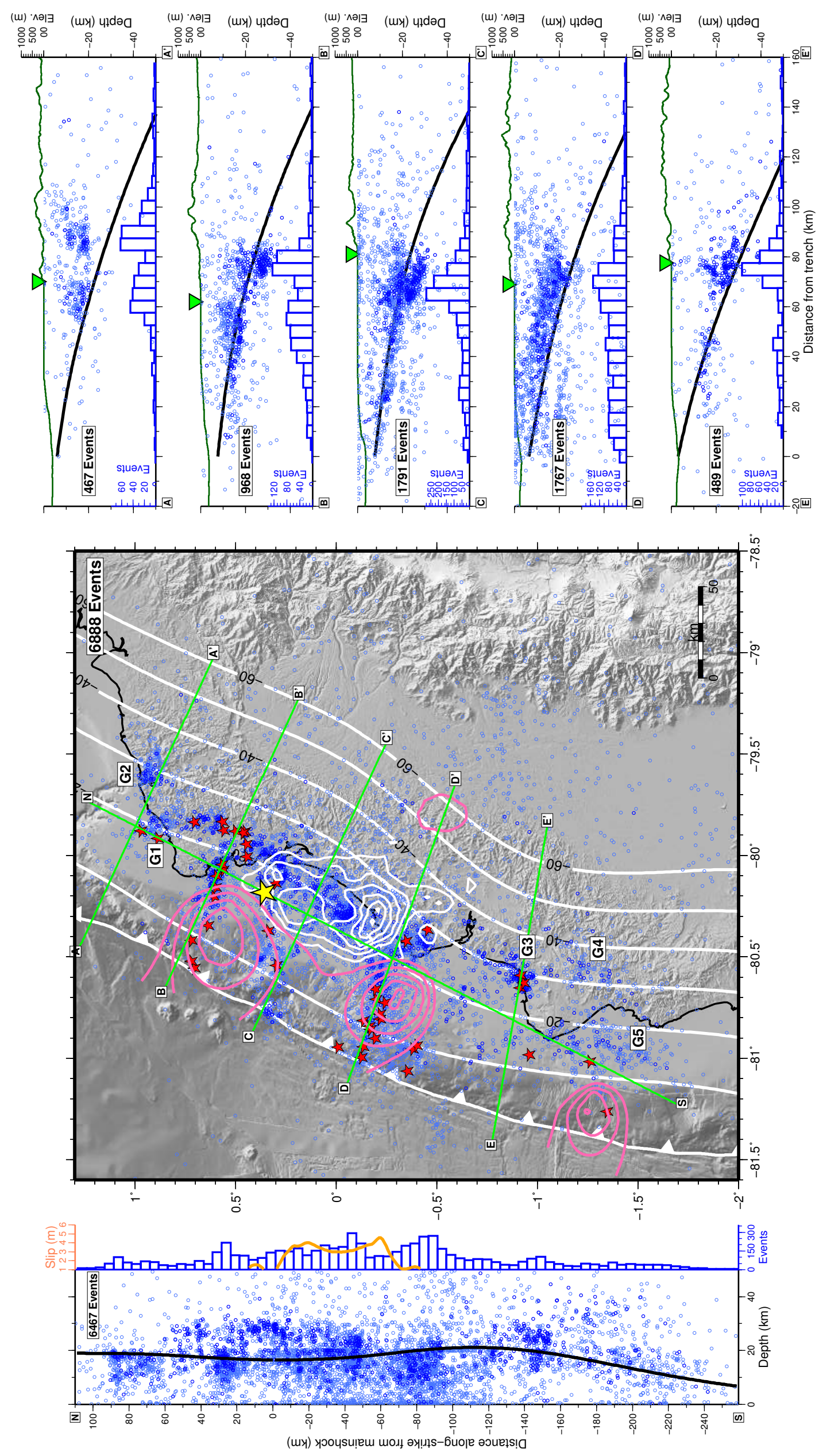
816 Figure 3 (previous page). Aftershock locations in map view and depth sections. Light blue circles show all first quality locations; dark blue circles show high accuracy locations with ellipse semi-axis errors less than $5 \mathrm{~km}$. Coseismic rupture model is shown as white contours every $1 \mathrm{~m}$ slip (Nocquet et al., 2017). Red stars are aftershocks with $\mathrm{M}_{\mathrm{L}}>=5$. Pink contours show afterslip every $10 \mathrm{~cm}$ (Rolandone et al., 2018). Clusters (G1-G5) indicate seismicity groups described in Section 3. Slab depth model (white lines in map, black line in depth sections) from Hayes, 2012. Histograms with blue bars show number of earthquakes for each profile. Histogram with orange line in N-S profile show distribution of coseismic slip along strike.
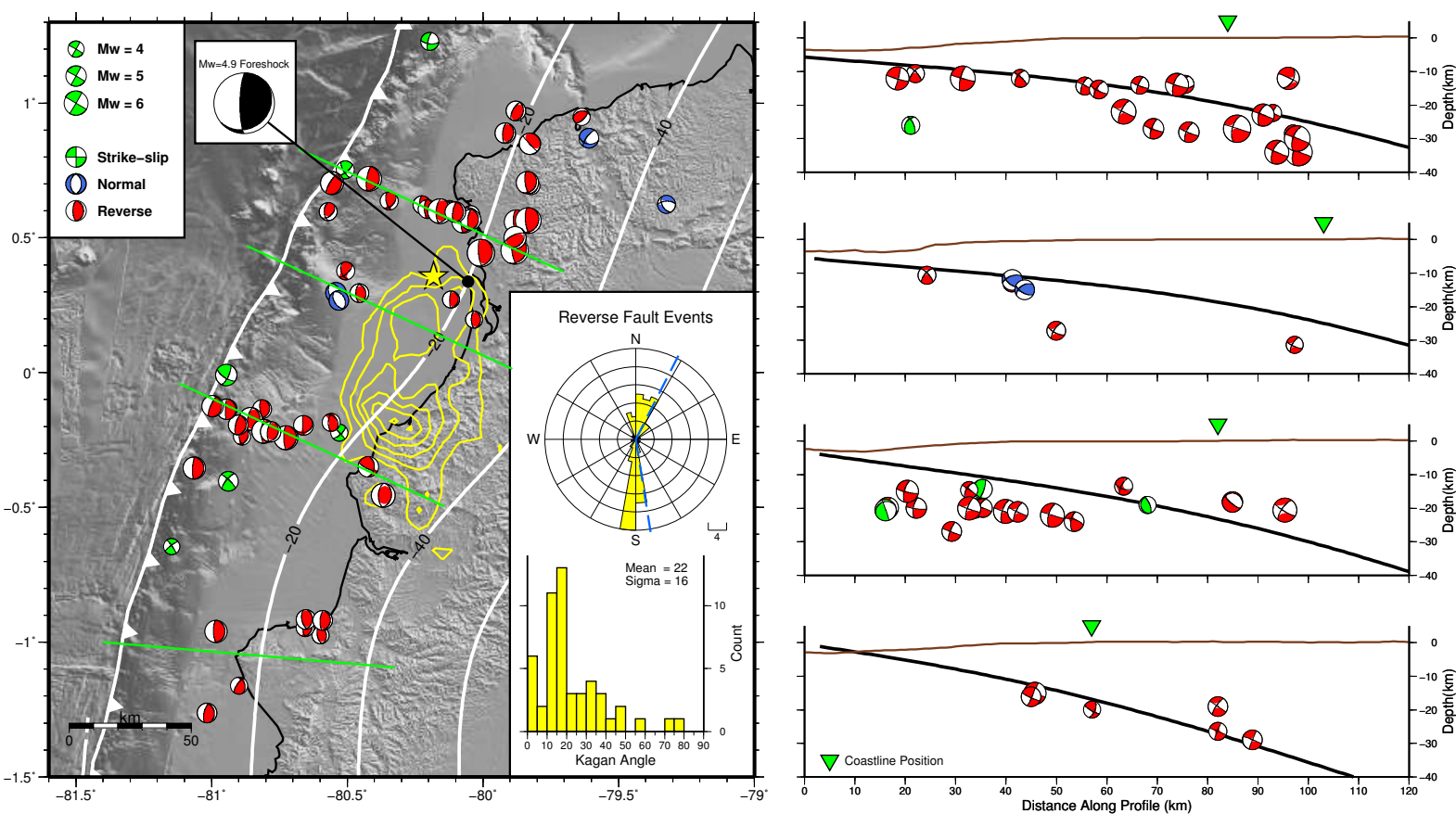

Figure 4. GCMT mechanisms and regional moment tensors obtained in this work.

Distribution shows epicentral location from this study for all events, and depth from computed centroid depth. Inset (top) rose histogram showing strike of nodal planes for all reverse fault mechanisms. Blue segmented line shows strikes of nodal planes for mainshock. Inset (bottom) shows histogram of rotational angle relative to mainshock mechanism for all reverse fault events. For details, see also Table 2 in Supplementary Material. 
848

849

850

851

852

853

854

855

856

857

858

859

860

861

862

863
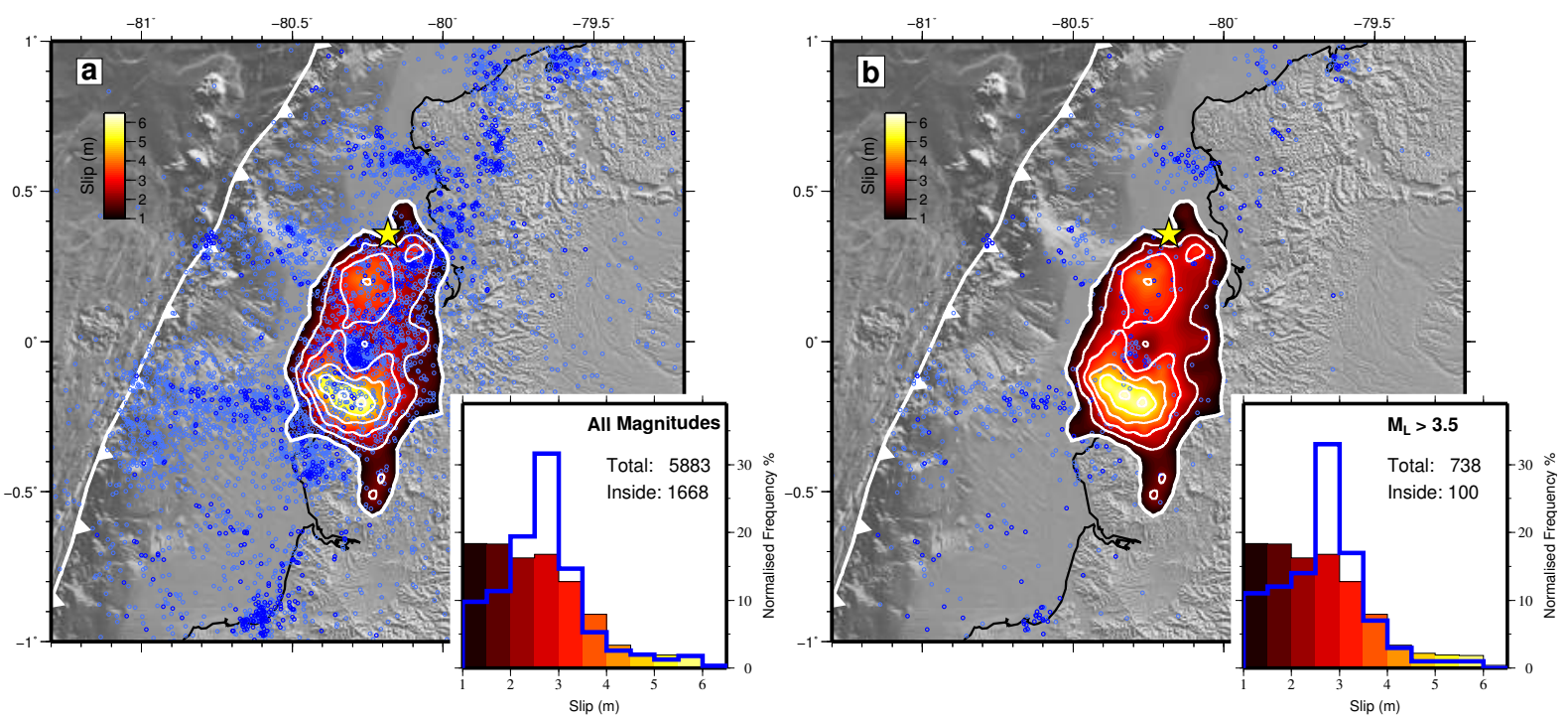

Figure 5. Distribution of aftershocks and coseismic rupture (Nocquet et al., 2017). (a) all magnitudes; (b) magnitudes equal or greater than 3.5. Histograms show normalized frequency distribution of coseismic slip (colour bars) and aftershocks (blue line).
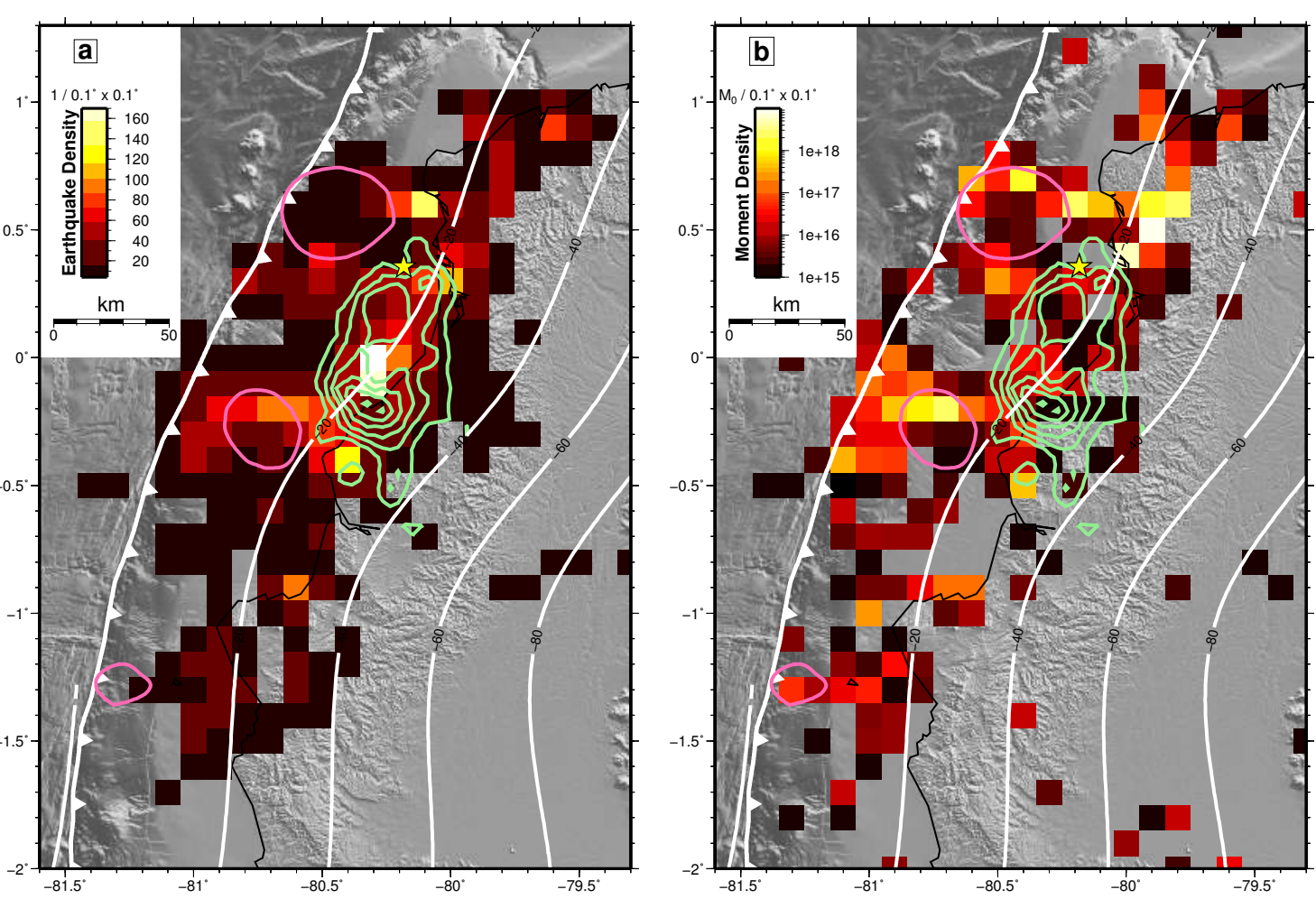

Figure 6. Density plots for (a) number of earthquakes, (b) seismic moment. Other features same as in Fig. 2. 

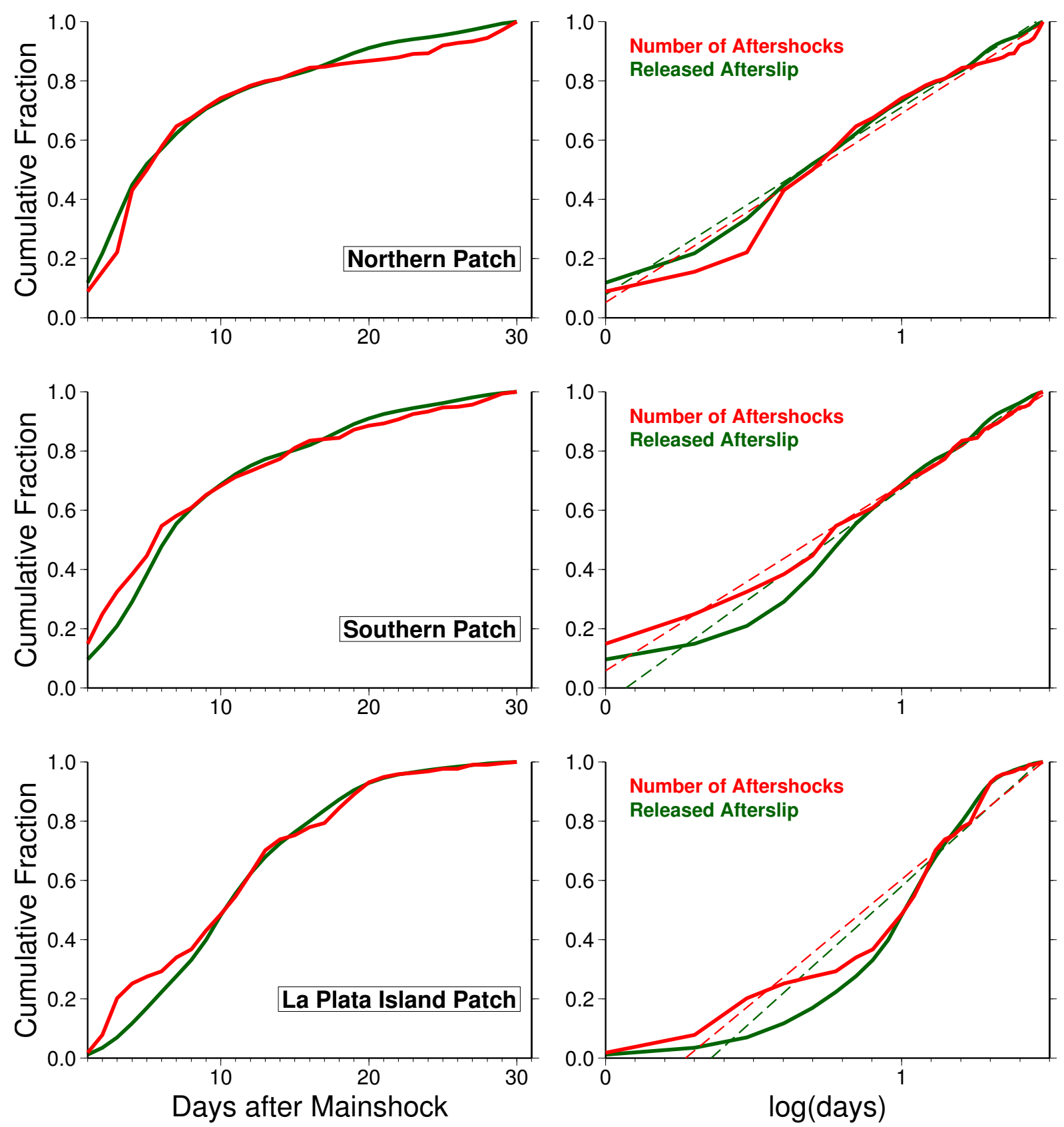

Figure 7. Temporal evolution of afterslip and aftershocks for the three different afterslip patches during the first 30 days following the mainshock. Released afterslip distribution after Rolandone et al. (2018). Left panels: cumulative distribution as a function of day. Right panels: cumulative distribution as a function of logarithm of day. Segmented line is best-

870 fitted straight-line. 
879

880

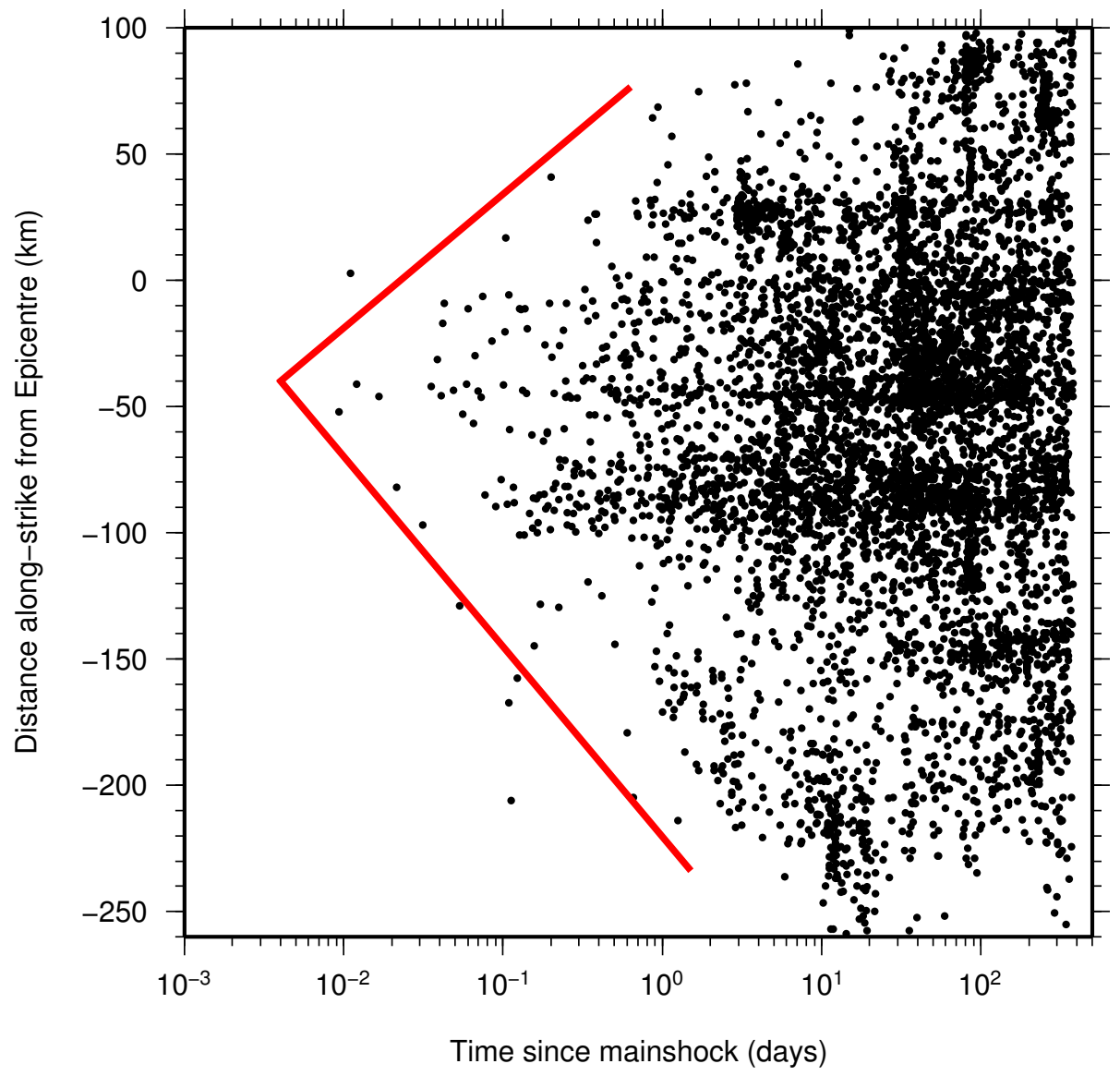

881

882

883

884

885

886

887

888

889

890

891

892

893

894

895

896

897

898

899

900

901

902

903

904

905

Figure 8. Expansion of earthquakes along strike in function of time since the mainshock. Red line indicates semi-logarithmic migration velocity of events (drawn by hand). 
906

907

908

909

910

911

912

913

914

915

916

917

918

919

920

921

922

923

924

925

926

927

928

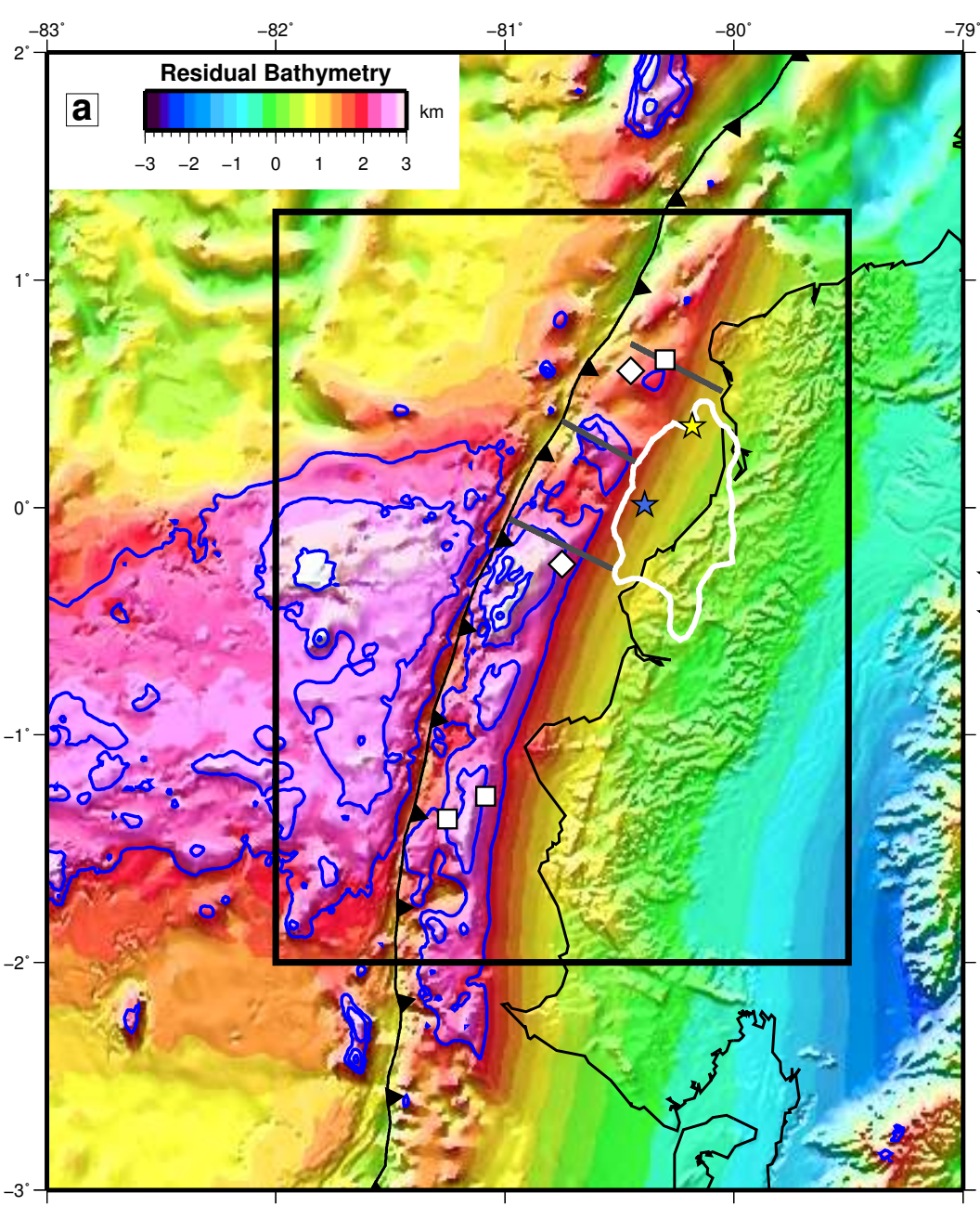

Figure 9. (a) Residual bathymetry and slip processes in the Ecuadorian margin. Blue contours every $500 \mathrm{~m}$ above $2000 \mathrm{~m}$ of residual bathymetry. Black box shows zoomed area in right-side panels. (b) interseismic (1943-2016) slip processes over residual bathymetry in grey scale. Seismicity from ISC catalogue. (c) postseismic slip processes (after 2016 mainshock) over residual bathymetry in grey scale.

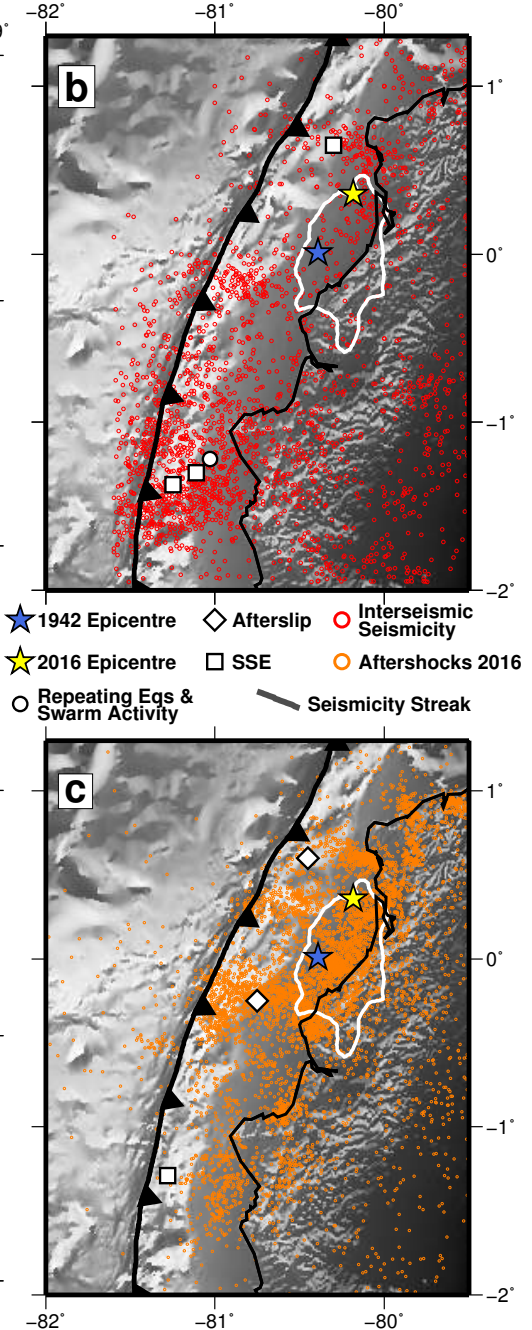




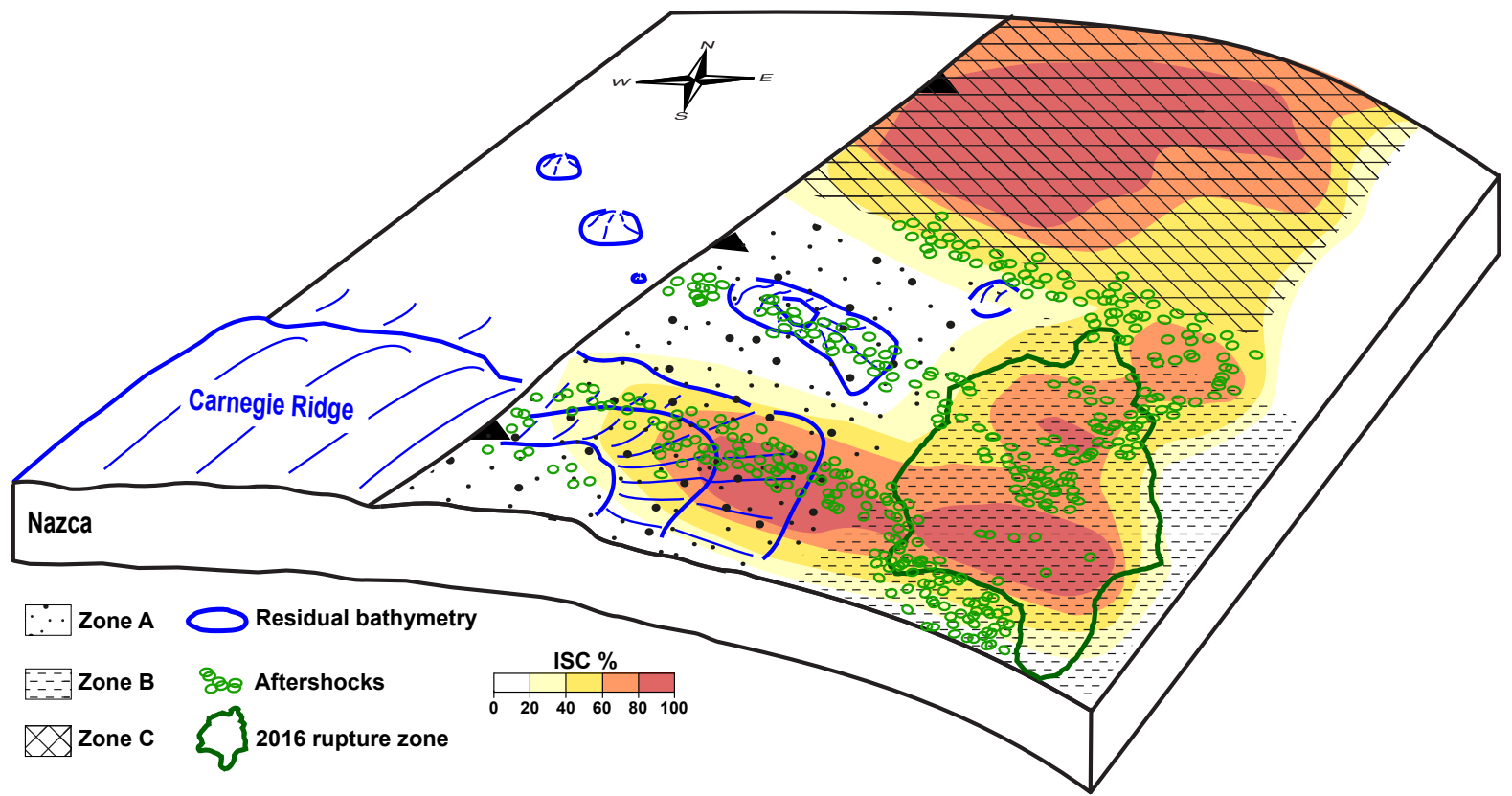

931

932

Figure 10. Schematic summary figure. We propose that the area influenced by the subduction of the $\mathrm{CR}$, as shown by the residual bathymetry contours, delimits the slip mode along dip and along strike in the Ecuadorian margin. Along dip, Zone A presents a rough and highly heterogeneous interface with the presence of fractures, possible fluids and overall low coupling. The interface at Zone A would be weak and seismically stable (velocity strengthening), and its slip mode is dominated by creeping, and includes SSE, repeating earthquakes, small to medium size $(\mathrm{M}<6)$ earthquakes and swarm activity, including the permanent bands of seismicity. Down dip, Zone B is less influenced by the CR, presenting an overall high coupling and a smoother interface allowing for large megathrust ruptures, although contained within $\sim 15$ to $40 \mathrm{~km}$ depth as in the case of the 1942 and 2016 ruptures. North of the CR along strike, Zone $\mathrm{C}$ is out of the influence of the CR and presents overall high ISC and large ( $\mathrm{M}>7.5)$ megathrust ruptures that occasionally can reach the trench as in the case of the 1906 earthquake. The interfaces of both Zones B and C therefore would be unstable/conditionally stable (velocity weakening). 